Please send trade news information and illustrations to Arveen Bajaj at the $B D J$, Nature Publishing Group, The Macmillan Building, 4-6 Crinan Street, London N1 9XW.

Trade news is provided as a service to readers using text and images from the manufacturer, supplier or distributor and does not imply endorsement by the $B D J$. Normal and prudent research should be exercised before purchase or use of any product mentioned.

\section{Hydrating coating technology}

Ansell Healthcare Europe, has announced the launch of HydraSoft, an new hydrating coating technology for surgical gloves. Designed to retain moisture and rehydrate users' skin during use, HydraSoft has been specifically developed for surgeons' hands, to help maintain the skin's natural barrier function. Composed of neutral, odourless ingredients in the gloves' inner lining, the product is designed to protect skin from drying, cracking and penetration by foreign substances.

It contains a skin-friendly, humectant moisturiser combined with dimethicone, which forms a protective barrier that blocks attacks from foreign substances and prevents the skin from drying out. Ansell plans to first introduce HydraSoft coating technology into its best-selling powderfree latex surgical glove, Gammex PF.

The introduction of HydraSoft has also permitted a modified formulation, resulting in a softer, suppler glove. The company is also set to integrate HydraSoft into other products within its medical glove range

Reader response number 50

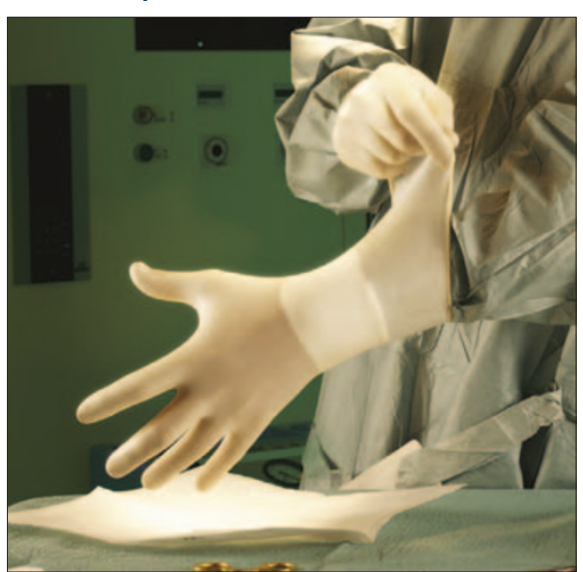

\section{TRADE NEWS \\ WHAT'S NEW}

\title{
Peroxide-free tooth whitener
}

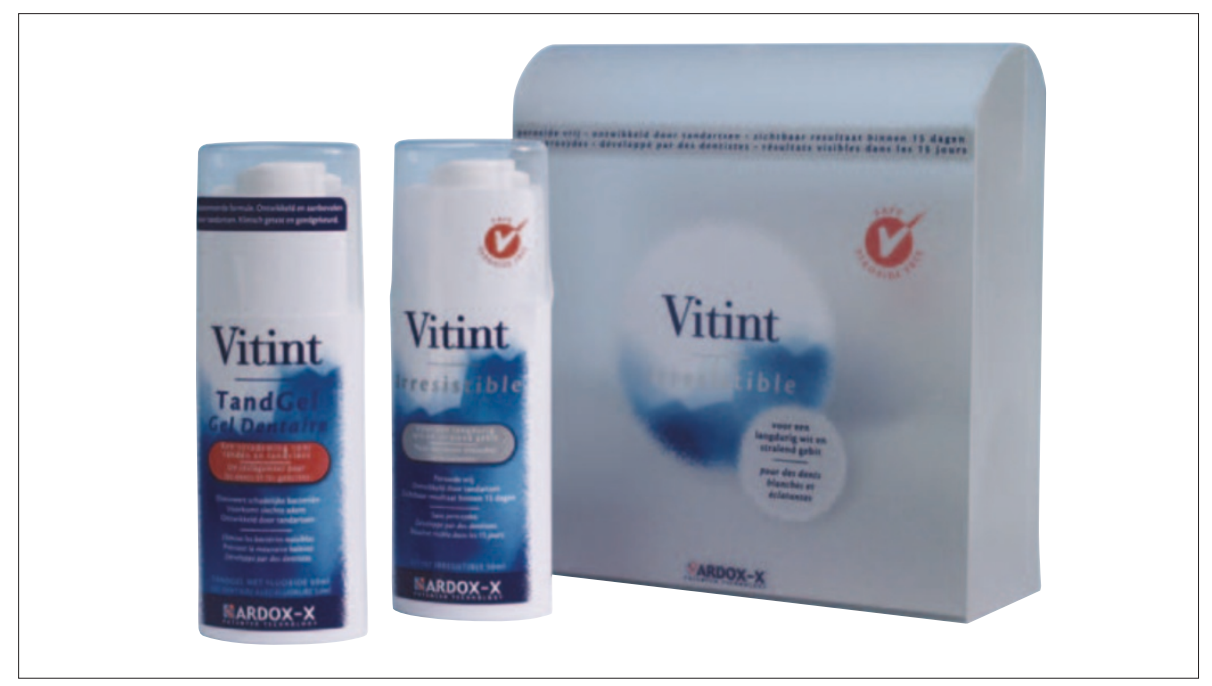

Vitint Irresistable, now available from Henry Schein, is a new product which helps to restore teeth's natural colour. Vitint Irresistable uses a unique, patented Ardox-X technology with stabilised oxygen, contains no peroxide or other bleaching agents, and is harmless to teeth and gums.

\section{Precise shade documentation}

The small, compact VITA Easyshade from VITA Zahnfabrik enables dental technicians and dentists to digitally determine exact tooth shade, independent of conditions of light. The tooth shade determined is either displayed in one of the 26 VITA system 3D-Master shades and the three VITA system 3D-Master Bleaching shades or in one of the 16 VITApan classical shades.

New software for the VITA Easyshade unit consists of two components - firmware and printer ware. The printer software offers users the advantage to connect the VITA Easyshade unit to a notebook or a PC. After shade taking users will be able to print or email measurements which document the data of the patient and the respective tooth situation by digital photo. Finally, an additional feature allows the user to draw in any anomalies.

Reader response number 52

\section{Turbine offer}

The Bien-Air special offer of three Bora LK turbines, with a free presentation case, will be available until the end of August 2005. The recommended retail price of this offer is $£ 1,650$ - a saving of $£ 100$ on the normal price with the addition of a free case, complete with removable autoclavable tray. The Bora LK, with light, is designed to connect with the Kavo Multiflex coupling, offering a high quality, cost effective option, without the need to change couplings.

Reader response number 53

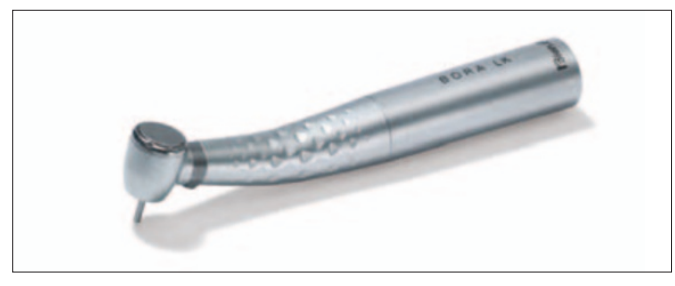




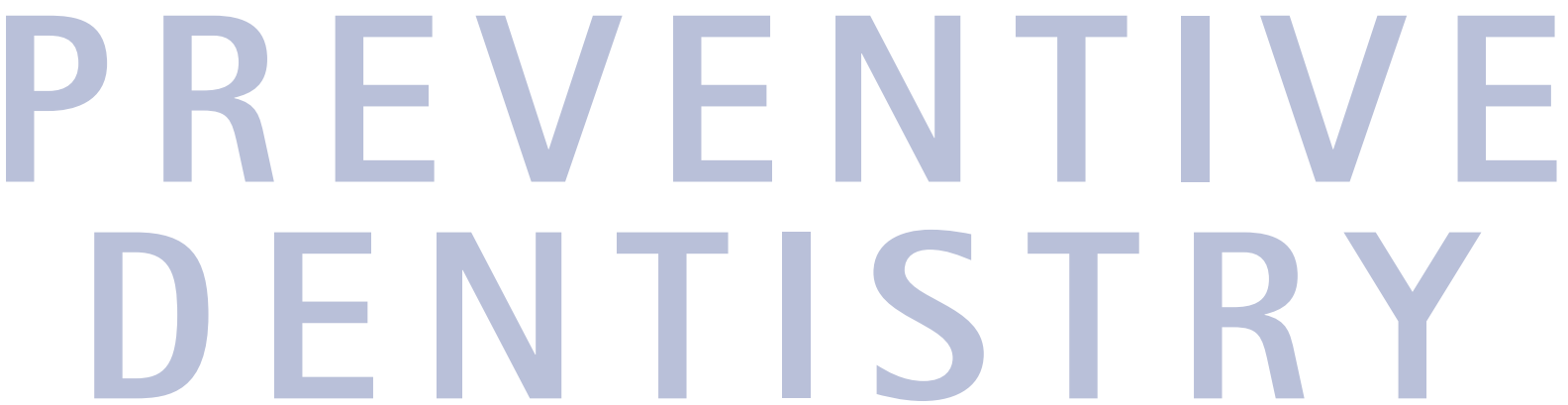

\section{Additive free toothpaste}

Sarakan Herbal Toothpaste is additive free and has recently been given accreditation from the British Dental Health Foundation. In addition, Sarakan does not contain sodium lauryl sulphate or any artificial preservatives.

Its origins are from a 'chewing stick' used in the Middle East to clean and massage teeth and gums.

The small portions of twig come from a specific shrub, salvadora persica (the toothbrush tree). Prior to use, the end of the twig is chewed or beaten with a stone to form a fibrous brush-like mass and the stick is then used to clean teeth and gently massage the gums, without any additional substance.

Sarakan contains the valuable extract of salvadora from 'the toothbrush tree' and is gently flavoured with the natural oil of peppermint, clove and geranium. Importantly it contains no alcohol or sugars, artificial colours or fluoride and is suitable for adults, children, vegetarians and vegans.

It is widely available from health food stores and selected pharmacies. In addition Sarakan Mouthrinse, also containing extract of salvadora, is an aid to a fresh and clean tasting mouth

Reader response number 54

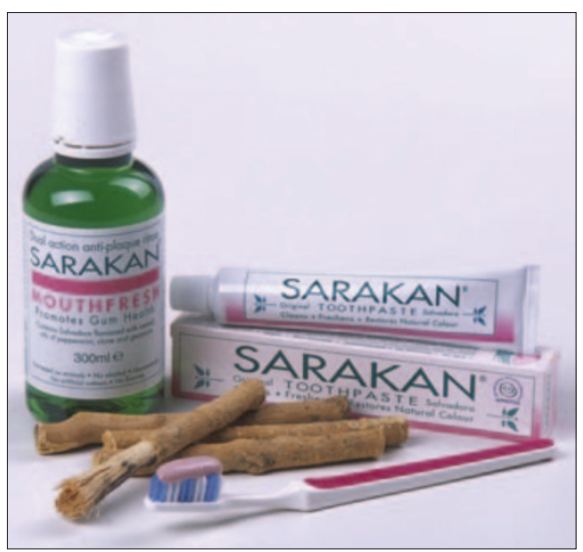

\section{Scaling and polishing solutions}

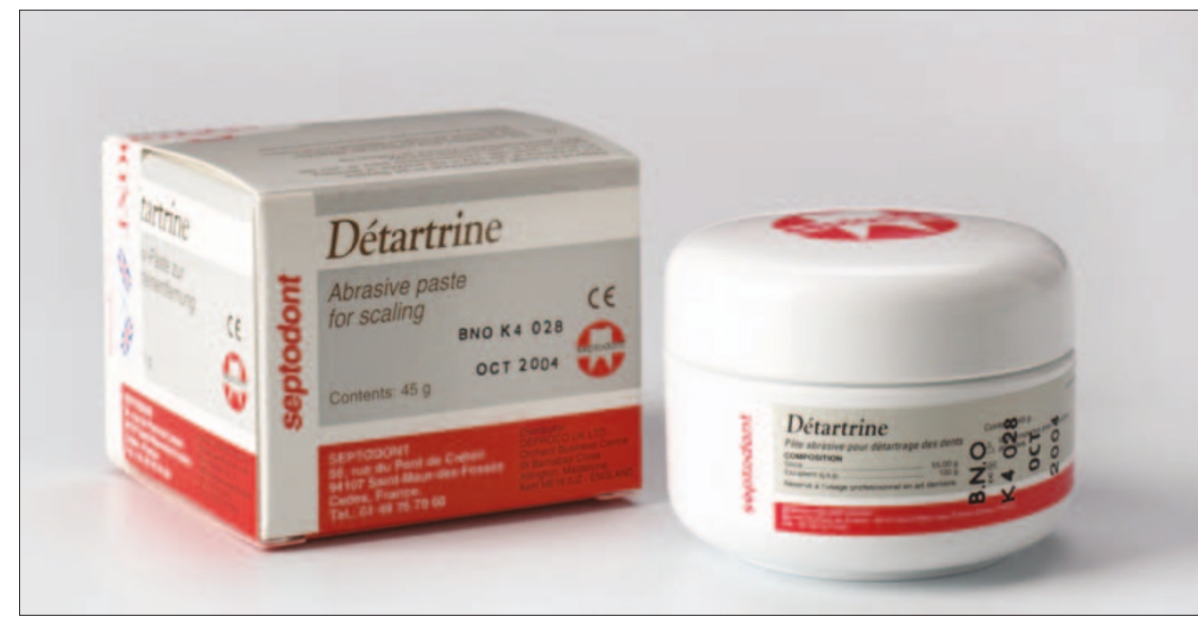

Septodont's Détartrine range offers dental professionals effective, gentle and pleasant tasting scaling and polishing solutions. Without eroding the dental enamel, silicone-based Détartrine is indicated for mechanical abrasion. The lemonflavoured pink paste can be used for finishing, scaling and eliminating stains or for the fine polishing of fillings. Détartrine $\mathrm{F}$ has the added benefits of fluoride, and can be used to polish fillings after scaling. The fine particles of the polishing agent,

zirconium oxide, brighten enamel, metallic restorations, acrylics and dental cements. The product also reduces the adherence of dental plaque, while the fluoride protects newly exposed enamel. Lastly Détartrine $\mathrm{Z}$ is a scaling paste with an abrasive action; rubbing the powder onto a rough surface smoothes and removes tartar without eroding the enamel. It can be used to prepare for polishing, eliminating anfractuosities and stains.

Reader response number 55

\section{Combination instruments}

Ash Instruments has range of luxation instruments which have a finely tapered tip and are effectively a combination of the characteristics of a periotome and an elevator. This combination allows their sharp tip to cut the periodontal ligament more efficiently, whilst the tapering shaft assists with controlled expansion of the bony socket.

A large proportion of extractions can become 'totally forceps free' and this can be especially valuable for younger patients as part of an orthodontic programme.

Ash Luxation instruments may also ensure better results, with less trauma to the site of extraction. The Ash Luxation kit comprises of four luxation instruments, a straight and curved blade in two different widths, a Ceramicolor Heidebrink Apical Elevator, a sharpening stone and finally a honing rod to keep the instruments in perfect condition.

Reader response number 56

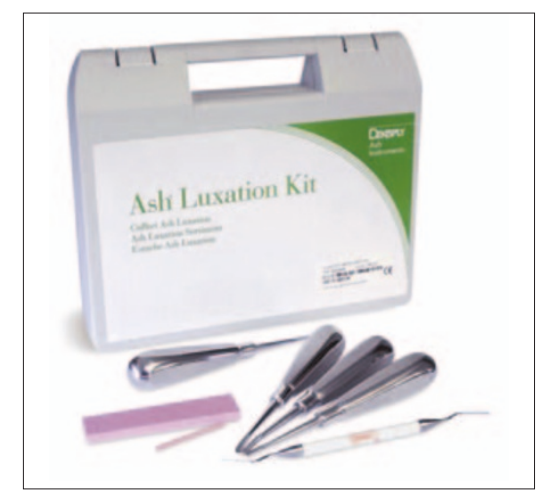




\section{Ultrasonic scaling}

Bellissima Ultrasonic Inserts from Dentsply offer a unique choice in 30K ultrasonic scaling by combining Cavitron inserts with a new soft, dimpled and comfortable grip. The Bellissima line of ultrasonic inserts provides various tip shapes enhanced with a new level of comfort. The $11.5 \mathrm{~mm}$ diameter grip increases comfort for the clinician, the soft grip design rotates easily in the hands and fingers and bright new colours - hot pink and purple - provide a more aesthetically appealing and user-friendly option to the classic FSI and FSISLI insert lines.

Reader response number 57

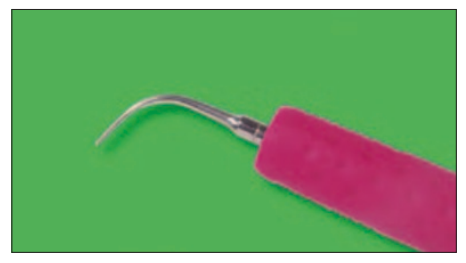

\section{Prevention for patients}

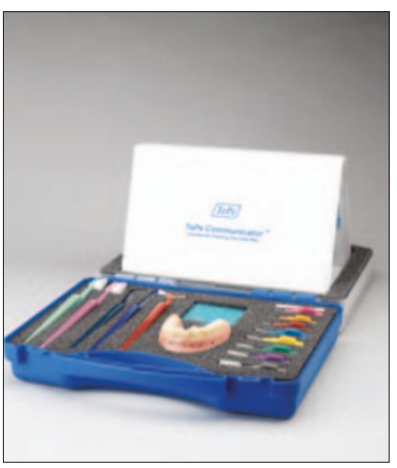

The TePe Communicator contains everything dental professionals need to demonstrate how to clean using the correct technique, perfect for education sessions with patients. It comes in a durable plastic case and includes a hand made lower dental arch with colourcoded spaces to show which TePe brush size should be used. Samples of TePe products including the eight sizes of interdental brushes, a Proximal, Interspace, Compact Tuft and TePe Select manual brushes are also included. A flip chart presenter with illustrations and patient leaflets complete the kit.

Reader response number 58

\section{Fibre optic illumination}

The Sirona scaler is an air-powered prophylactic handpiece for removing plaque which is made easier with the addition of fibre optic illumination by a powerful ring light. The Siroair L has three different power settings that can be regulated by the built-in control on the handpiece to suit specific circumstances for the amount of plaque removal and cleaning capabilities.

Fibre optic illumination is incorporated to provide optimum light in all areas, and six tips are available for utilising most scaling and polishing procedures. The Sirotip changer ensures that all tips can be interchanged quickly and efficiently and can also be used as a protective cap during sterilisation. The handpiece will fit quickly and easily to a coupling on the dental unit without the need for separate foot control and water supply and may be sterilised in an autoclave at up to $135^{\circ} \mathrm{C}$.

Reader response number 59

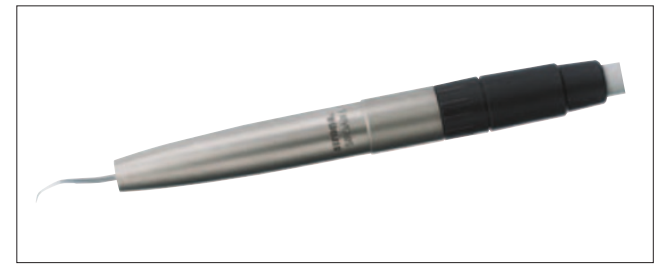

\section{Non-sticky sealant}

Dentsply offers a full range of preventive materials, such as Delton, a low viscosity, smooth flowing, non-sticky pit and fissure sealant, which ensures absolute penetration of the fissure and intricate interdental spaces, and can make treatment easier. In addition, with increasing importance placed on cross-infection control, the Delton DDS (lightcured) unit dose is can minimise the risks of patient-to-patient contamination. Available

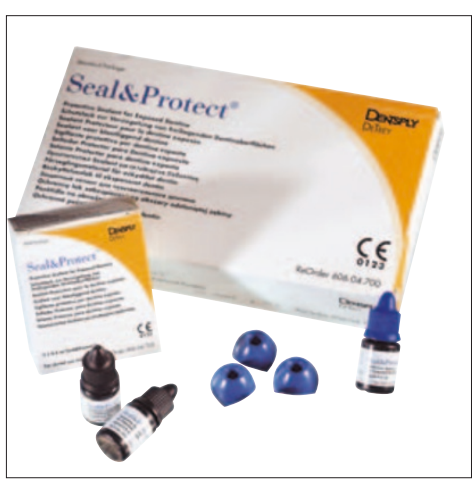
as Delton Self Cure, Light Cure and the Light Cure direct delivery system (DDS), most lines are available in clear or opaque.

Nupro premium prophylaxis paste offers a low splatter formula in mint or orange flavours and in economy jars or unit-dose cups while Seal \& Protect offers a simple solution to treating hypersensitivity and offers extra protection for exposed dentine to prevent further problems and damage. Lastly Cavitron Prophy Jet powder now has an improved mint flavour and is ideal for effective fissure cleaning.

Reader response number 60 